\title{
MICROBIOLOGICAL PROFILE OF BACTERIAL CONJUNCTIVITIS IN IBADAN, NIGERIA
}

A.O. Okesola and A.O. Salako

Department of Medical Microbiology and Parasitology, College of Medicine, University of Ibadan, University College Hospital, Ibadan, Nigeria

Correspondence:

Dr. A.O. Okesola,

Dept. of Medical Microbiology and Parasitology, College Of Medicine,

University College Hospital,

Ibadan, Nigeria, West Africa.

Phone: 234- 803-305-0593

E-mail: abiolaokesola@yahoo.com aookesola@comui.edu.ng

\section{SUMMARY}

Objective: In bacterial conjunctivitis, clinical presentations are not diagnostic of the causative agent, therefore, microbiological analysis is mandatory for specific treatment option. This study was undertaken to determine the microbiology profile of bacterial conjunctivitis in our environment.

Methodology: This is a laboratory-based study carried out in the Medical Microbiology Laboratory of University College Hospital, Ibadan, Nigeria. Conjunctival swabs collected from 365 patients with clinically diagnosed conjunctivitis, were analysed by standard bacteriological methods.

Results: Bacterial pathogens were detected in 342 (93.7\%) conjunctival samples while $23(6.3 \%)$ were sterile. Of the pathogens, 256 (74.9\%) were Staphylococcus aureus, 35(10.2\%) Coagulase- negative staphylococci, 22 (6.4\%) Pseudomonas aeruginosa, 11(3.2\%) Escherichia coli, 7(2.1\%) Klebsiella species, 5(1.5\%) Streptococcus pneumoniae, 4(1.2\%) Haemophilus influenzae, 1(0.3\%) Proteus mirabilis and 1(0.3\%) Neisseria gonorthoeae. The highest rate of conjunctivitis $96(26.3 \%)$ was found among infants and children (0-10years). Resistance rates to most of the tested antibiotics were high. However, $67 \%$ of them were susceptible to ceftriaxone while only $39.2 \%$ were susceptible to chloramphenicol.

Conclusions: This study has recorded high antibiotic resistance in bacterial pathogens of conjunctivitis in this environment; therefore, determining the susceptibility pattern of these pathogens to available antibiotics is crucial to effective management of bacterial conjunctivitis.

Keywords: Conjunctivitis, bacteria, microbiological profile

\section{INTRODUCTION}

Bacterial conjunctivitis is common and affects all age groups. They are mainly caused by bacteria such as Streptococcus pneumoniae, Haemophilus influenzae, Staphylococcus aureus and Neisseria gonorrboeae in the normal host. In the new born, who often get this infection from the vaginal fluids of their mothers during birth, N.gonorrboea and Cblamydia trachomatis are the most common causes ${ }^{1,2}$ S.pneumoniae, P.aeruginosa, and S. aureus may also cause acute conjunctivitis in neonates or children ${ }^{3}$ In sexually active teenagers and adults, C.trachomatis and N.gonorrboea have been implicated. In young children, H.influenzae can cause severe conjunctivitis. ${ }^{4}$ In adults, isolates are S.pneumoniae, S.aureus, and Staphylococcus epidermidis ${ }^{5}$, Serratia marscences, ${ }^{6}$ S.pneumoniae, P.aeruginosa ${ }^{7}$ and Moraxella species have been implicated in institutional outbreaks of bacterial conjunctivitis. Gonococcal conjunctivitis rarely occurs without sexual transmission, and suspicion for possible sexual abuse should be maintained in prepubertal children. ${ }^{8}$ Neisseria meningitidis, however, is an uncommon cause of acute bacterial conjunctivitis.

Typically, transmission of the infection involves exogenous routes of infection via airborne fomites, handto-eye contact, contact with genital secretions and contact with upper respiratory tract infection secretions. Less frequently, infection may spread to the conjunctiva from the eyelids, lacrimal drainage apparatus, face, or paranasal sinuses. Hematogenous route of infection is however rare. The most common presentation 
is a red eye and the main tasks are to exclude potentially serious causes of a red eye and then decide whether the conjunctivitis is infective, allergic, or due to other causes, so that a suitable management could be instituted. Clinical presentations are not diagnostic of the causative agent, therefore microbiological analysis, with cytology, cultures, and microbial susceptibilities are mandatory. The specific antimicrobial therapy should then be based on the laboratory findings. ${ }^{9}$ This study was therefore designed to determine the prevalence and pattern of antibiotic susceptibility among bacterial pathogens of conjunctivitis in our environment.

\section{METHODOLOGY}

This is a laboratory-based study conducted in the diagnostic Medical Microbiology Laboratory of University College Hospital, Ibadan, Nigeria, between September 2002 and October 2003.

\begin{tabular}{|l|l|}
\hline A ge (Years) & No (\%) \\
\hline$<10$ & $96(26.3)$ \\
\hline $10-20$ & $18(4.9)$ \\
\hline $21-40$ & $40(11)$ \\
\hline $51-60$ & $58(15.9)$ \\
\hline$>60$ & $86(23.6)$ \\
\hline Unspecified & $67(18.4)$ \\
\hline Total & $\mathbf{3 6 5 ( 1 0 0 . 1 )}$ \\
\hline & \\
\hline Sex & No (\%) \\
\hline M a le & $216(59.2)$ \\
\hline Female & $149(40.8)$ \\
\hline Total & $\mathbf{3 6 5 ( 1 0 0 . 0 )}$ \\
\hline
\end{tabular}

Tab le 1. D istribution of patients with bacterial conjunctivitis by age and sex

\section{Specimen collection}

Three hundred and sixty-five conjunctival swabs sent to Medical Microbiology Laboratory for analysis were separated from other specimens for the purpose of this study.

These were collected in the Eye clinic of University College Hospital by ophthalmologists, from patients with clinically diagnosed conjunctivitis.

\section{Isolation and identification of bacterial eye pathogens}

The conjuctival swabs were inoculated on Blood agar, MacConkey agar and Chocolate media and incubated at $37^{\circ} \mathrm{C}$ for $24 \mathrm{hrs}$. Discrete colonies of bacterial isolates recovered were subjected to Gram-staining and various biochemical tests for identification.

\section{Antiobiotic susceptibility testing}

Preparation and standardization of inocula

Standard bacterial suspensions were prepared as follows: Colonies of each strain of bacterial isolate were

\begin{tabular}{|l|l|}
\hline B acterial Pathogen & No (\%) \\
\hline Staphylococcus aureus & $256(74.9)$ \\
\hline Pseudomonass aeruginosa & $22(6.4)$ \\
\hline Eschericbia coil & $11(3.2)$ \\
\hline Coagulase-nega tive staphylococci & $35(10.2)$ \\
\hline Klebsiella species & $7(2.1)$ \\
\hline Streptococcus pneumonia & $5(1.5)$ \\
\hline Haemophilus influen zae & $4(1.2)$ \\
\hline Proteus mirabilis & $1(0.3)$ \\
\hline Neisseria gonorrboeae & $1(0.3)$ \\
\hline Tot al & $\mathbf{3 4 2 ( 1 0 0 . 1 )}$ \\
\hline
\end{tabular}

Table 2. Distribution of bacterial pathogens of conjunctivitis

emulsified in $3 \mathrm{ml}$ volume of saline to the turbidity of $0.5 \mathrm{MacF}$ arland standards.

\section{Procedure for SensitivityTesting}

Sterile swabs were then dipped into these standard bacterial suspensions and plated on Mueller-Hinton agar sensitivity plates. The plates were covered for five minutes to dry. Various antibiotic sensitivity discs (six per plate) were placed on each plate and incubated at $37^{\circ} \mathrm{C}$ for 24 hours. ${ }^{10}$ The bacterial pathogens were tested against the following antibiotics: gentamycin, erythromycin, ceftriaxone, ofloxacin, chloramphenicol, amoxycillin / clavulanate, amoxycillin and cloxacillin. These were the antibiotics that were readily available in the environment under study. After $24 \mathrm{hrs} \mathrm{incu-}$ bation, the plates were examined for zones of inhibition around each of the antibiotic disc.

These were measured and compared with interpretive chart to determine the sensitive and the resistant strains.

Demographic information regarding age and sex of patients were also obtained and recorded. The prevalence rate of methicillin-resistant $S$. aureus among the $S$. aureus strains isolated was, however, not determined in this study.

\section{RESULTS}

Three hundred and forty-two bacterial pathogens were isolated and identified from the conjunctival swabs of three hundred and sixty-five patients with clinically diagnosed conjunctivitis at the eye clinic of University College Hospital, Ibadan, South Western Nigeria.

These patients consisted of $216(59.2 \%)$ males and $149(40.8 \%)$ females, and they were aged between 3 months and 88 years (Table 1). Bacterial pathogens were detected in the conjunctival samples of 342 $(93.7 \%)$ patients, while $23(6.3 \%)$ showed no growth. 
Two hundred and fifty-six $(74.9 \%)$ of the pathogens identified were Staphylococcus aureus, 22(6.4\%) Psendomonas aeruginosa, 11(3.2\%) Escherichia coli, 35(10.2\%) coagulase-negative staphylococci, $7(2.1 \%)$ Klebsiella species, 5(1.5\%) Streptococcus pneumoniae, 4(1.2\%) Haemophilus influenzae, $1(0.3 \%)$ Proteus mirabilis, and 1(0.3\%) Neisseria gonorrboea (Table 2). Two hundred and ninety-six $(86.5 \%)$ of these bacterial pathogens were Gram-positive bacteria, while only 46 (13.5\%) were Gram-negative (Table 3). The in vitro susceptibility pattern of these bacterial pathogens to antibiotics as assessed by the antibiotic disc diffusion test is shown in Table 4.

\begin{tabular}{|l|l|l|}
\hline Isolates & Number & $\mathbf{\%}$ \\
\hline Gram-positive & 296 & 86.5 \\
\hline Gram-negative & 46 & 13.5 \\
\hline Total & $\mathbf{3 4 2}$ & $\mathbf{1 0 0 . 0}$ \\
\hline
\end{tabular}

Table 3. Distribution pattern of Gram-positive and $\mathrm{Gram}$-negative pathogens in bacterial conju nctivitis.

\section{DISCUSSION}

The present study has shown that the most common bacterial pathogen of conjunctivitis in this environment is Staphylococcus aureus, being responsible for $74.9 \%$ of all cases. This is in keeping with some other studies which have demonstrated the same trend. 3,5 The prevalence of methicillin resistance among the isolated S.aureus responsible for bacterial conjunctivitis in this study was not determined, therefore, further studies will need to be done in this regard. However, a study conducted by Okesola et al in 1999 in the same hospital, showed a prevalence rate of $12 \%$ among the strains of S.aureus isolated. ${ }^{11}$ Cavuoto et al in 2003 reported an increase from $4.4 \%$ in 1994 to $42.9 \%$ in 2003 of MRSA isolates from paediatric patients with bacterial conjunctivitis. ${ }^{12}$ Taiwo and his colleagues in 2001 reported a prevalence rate of $34.7 \%$ of MRSA among S.aureus isolates in Ilorin, in the North Central part of Nigeria. ${ }^{13}$ The highest rate of bacterial conjunctivitis was found among infants and children (0-10 years). The rate was also higher in males $(59.2 \%)$ than in females $(40.8 \%)$.

The susceptibility pattern of pathogens to antibiotics is variable in this study; however, recent studies have shown increasing resistance of bacterial pathogens of conjunctivitis to many antibiotics ${ }^{9}$. The same was the case in the present study where the resistance rates to many of the antibiotics were rather high. The pathogens demonstrated relatively good susceptibilities to erythromycin $(57 \%)$ and ceftriaxone $(67 \%)$ but susceptibilities to the remaining antibiotics were rather poor, $31.3 \%$ to amoxicillin, $42.7 \%$ to amoxicillin/

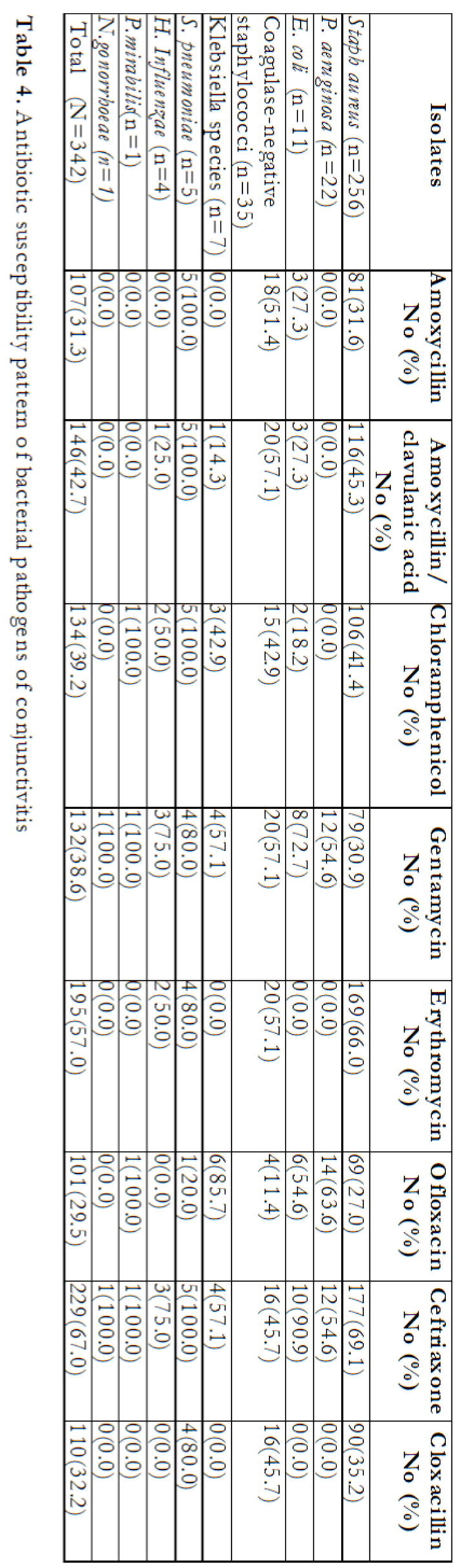


clavulanate, $39.2 \%$ to chloramphenicol, $38.6 \%$ to gentamycin, $29.5 \%$ to ofloxacin and $32.2 \%$ to cloxacillin. In the present study, susceptibility rate to chloramphenicol was $39.2 \%$, but in a study conducted by Modarres et al, the susceptibility was reported to be approximately $84 \% .{ }^{14}$ Similarly, Adegbehingbe, in a study conducted in Ile-Ife, Nigeria in 2000, reported susceptibility rate of $68.9 \%$ to chloramphenicol and $89.8-97.8 \%$ to ciprofloxacin, a quinolone ${ }^{15}$. In our study, however, susceptibility to ofloxacin, another quinolone, was $29.5 \%$. Ofloxacin, rather than ciprofloxacin was included in this study because it was more commonly used in our hospital to treat bacterial conjunctivitis. The low susceptibility to these agents observed in this study, may be due to increased rate of abuse of these antibiotics especially ofloxacin and chloramphenicol in our community. Staphylococcus aureus, the most prevalent pathogen in our study was most susceptible to ceftriaxone $(69.1 \%)$, and least to ofloxacin $(27 \%)$, an antibiotic that is commonly used for bacterial conjunctivitis in the study location.

The various antibiotics used to treat bacterial conjunctivitis in Nigeria are either used topically or systemically or both depending on the severity of the condition or the type of pathogen involved. Gonococcal conjunctivitis, however, is treated both systemically and topically because of the usual source of infection which is the genitourinary tract.

\section{CONCLUSIONS}

In Nigeria, many physicians start therapy empirically without culturing the conjunctiva and, laboratory investigations are ordered for only after treatment has failed. Unfortunately, antibiotic resistance is increasing among these conjunctival pathogens. Moreover, susceptibility of the bacterial pathogens to the common ophthalmic antimicrobial agents is rather low as demonstrated in this study. Therefore, determining the susceptibility pattern of these pathogens to the commonly available antibiotics is of utmost importance in the effective management of bacterial conjunctivitis.

Further studies also need to be done to determine the prevalence rate of methicillin resistance among the strains of S.aureus isolated as pathogens of conjunctivitis in this environment and their molecular characterization.

\section{ACKNOWLEDGEMENTS}

The authors are grateful to Mrs Agboola and Mrs Popoola for their technical and secretarial assistance respectively.

\section{REFERENCES}

1. de Toledo A.R., and Chandler J.W. Conjunctivitis of the new born. Infect Dis Clin North Am.1992;6:807-813.

2. Ratell S., Keno D., Hardwood M. and Etkind P.H. Neonatal chlamydial infections in Massachusetts.1992-1993. Am J Prev Med.1997;13:221-224.

3. Buznach N., Dagan R and Greenberg D. Clinical and bacterial characteristics of acute bacterial conjunctivitis in children in the antibiotic resistance era. Pediatr Infect Dis J 2005;24:823-828.

4. Trottier S., Stenberg K., VonRosen I.A. and Svanberg C. Haemophilus influenzae causing conjunctivitis in day-care children. Pediatr Infect Dis J. 1991; 10: $578-584$.

5. Seal D.V., Barrett S.P. and McGill J.I. Aetiology and treatment of acute bacterial infection of the external eye. Br J Ophthalmol. 1982;66:357.

6. Van Ogtrop M.L., Van Zoeren- Groggen D, Verbakel-Salomms E.M. and Van Boven C.P. Serratia marcescens infections in neonatal departments: Description of an outbreak and review of the literature. J Hosp Infect.1997;36:95-103.

7. Brito D.V., Oliveira E.J., Matos C., et al. An outbreak of conjunctivitis caused by multiresistant Pseudomonas aeruginosa in a Brazilian newborn intensive care unit. Braz J Infect Dis.2003; 7(4) : 234235.

8. Lewis L.S., Glauser T.A. and Joffe E. Gonococcal conjunctivitis in pre-pubertal children. Am J Dis Child.1990;109:96-97.

9. Kowalski R.P., Karenchak L.M. and Romanowski E.G. Infectious disease: changing antibiotic susceptibility. Ophthalmol Clin North Am 2003;16(1-9):13.

10. National Committee for Clinical Laboratory Standards. Performance Standards for antimicrobial susceptibility testing. $11^{\text {th }}$ informational supplement. NCCLS Document M100-S11. 2001.

11. Okesola A.O., Oni A.A. and Bakare R.A. Prevalence and antibiotic sensitivity pattern of methicillin-resistant Staphylococcus aureus in Ibadan. J Hosp Inf 1999; 41 (1):74-75. 
12. Cavuoto K., Zutshi D., Karp C.L., et al. Update on bacterial conjunctivitis in South Florida. Ophthalmology 2008;115:51-56.

13. Taiwo S.S., Onile B.A. and Akanbi A.A. Methicillin-resistant Staphylococcus aureus (MRSA) isolates in Ilorin, Nigeria Afr J Clin Exp Microbiol 2001:189197.
14. Moderres A., Lasheli A., and Oskoli N.N. Bacterial etiologic agents of ocular infection in children in the Islamic Republic of Iran. East. Med H J. 1998; 4(1):44-49.

15. Adegbehingbe B.O., and Onipede A.O. Conjunctivitis as seen in Ile-Ife. Nig J Ophthalmol $2005 ; 13$ (1) : 21-26 